\title{
Challenges in the Clinical Environment: The Saudi Student Nurses' Experience
}

\author{
Ahmad E. Aboshaiqah $\left(\mathbb{D},{ }^{1}\right.$ Irene M. Roco ${ }^{D},{ }^{2}$ Isabelita N. Pandaan, ${ }^{2}$ Omar G. Baker (D), \\ Regie B. Tumala $\oplus^{2},{ }^{2}$ and John Paul Ben T. Silang $\oplus^{3}$ \\ ${ }^{1}$ Nursing Administration and Education Department, College of Nursing, King Saud University, Riyadh 11421, Saudi Arabia
${ }^{2}$ Medical Surgical Nursing Department, College of Nursing, King Saud University, Riyadh 11421, Saudi Arabia
${ }^{3}$ College of Nursing, King Saud University, Riyadh 11421, Saudi Arabia
}

Correspondence should be addressed to Ahmad E. Aboshaiqah; aaboshaiqahksu@gmail.com

Received 17 April 2018; Revised 24 October 2018; Accepted 29 October 2018; Published 2 December 2018

Academic Editor: Gwo-Jen Hwang

Copyright ( 2018 Ahmad E. Aboshaiqah et al. This is an open access article distributed under the Creative Commons Attribution License, which permits unrestricted use, distribution, and reproduction in any medium, provided the original work is properly cited.

\begin{abstract}
Previous studies showed that student nurses faced difficulties in clinical practice; thus, this study examined the clinical challenges encountered by Saudi nationals and the implications to learning outcomes using the descriptive cross-sectional approach. The study was conducted in nursing college in a university in Riyadh, Saudi Arabia. The survey questionnaires were completed by 220 conveniently selected student nurses who were enrolled in Bachelor's Degree in Nursing from the academic level 5 to 8 . Data analysis was done through the Statistical Package for the Social Sciences version 23. Clinical evaluation was perceived as the most common challenge, whereas competency development as the least. Significant associations were found between age and evaluation, academic level and competency development, and grade point average and learning outcomes. Nursing competency development significantly varied with civil status and stream of study. Students in the Regular Nursing Program faced more challenges in achieving learning outcomes then their counterparts. Overall, the challenges were perceived as occasional. Resolving clinical obstacles is crucial in helping student nurses achieve positive learning outcomes.
\end{abstract}

\section{Introduction}

In Saudi Arabia, nationals prefer other professions than nursing because of the numerous clinical challenges facing the nurse practitioners. These challenges include concerns on the regulation of professional standards, formation of Saudi nursing organizations, societal negative image of nursing, and the accreditation of the various nursing programs $[1,2]$. The Bachelor of Science in Nursing (BSN) in Saudi Arabia has evolved over time. Diploma and associate degrees were established by the Ministry of Health (MOH) which transitioned to BSN and now managed by the Ministry of Education (MOE). At present, the nursing program is offered as either Regular Nursing Program (RNP) or a Nursing Bridging Program (NBP). The enhancement of nursing programs demand long-term planning and benchmarking from other countries with advanced nursing education. The varied educational systems have overwhelmed nursing job descriptions and teaching methodologies of the nursing program in Saudi Arabia [3].

Nurses with good competencies are essential in the health care system. Acquiring nursing competencies requires quality nursing education which helps students gain the necessary knowledge, skills, and attitude in providing nursing care [4]. The clinical education can also affect the growth and development of competence on nursing skills [5]. Universities are projected to offer ideal learning environment which can empower student nurses to maximize their potential in performing nursing roles. The experiences are also vital for the enhancement of teaching strategies and revisions of the BSN curriculum [6]. Thus, student nurses play a critical part in the evaluation of the clinical environment where they gain learning [7].

Clinical learning is an interactive network of forces which impacts the learning outcomes in the real world [8]. In this phase, the student nurses are expected to learn the basic 
nursing courses while they are in the academic environment. In hospitals and other health care facilities, the student nurses apply relevant concepts to clinical practice with faculty or preceptors. Preceptors supervise, teach, or assist student nurses in acquiring the necessary competencies. Students are trained in the clinical area to further acquire learning with real patients in collaboration with other health care team members.

In Saudi Arabia, clinical learning in the hospitals entail many challenges brought about by numerous factors including time pressure which is everyone's adversary [9]. According to Hosoda [10], the clinical environment could be a source of stress and anxiety which challenges the students' learning ability. It is by this context that the researchers opt to conduct this study to identify the challenges faced by Saudi student nurses in their clinical exposures.

Saudi student nurses perceived learning in clinical settings as relatively low throughout their experience. The dissatisfaction was associated with the lack of exposure to actual patients, improper orientation on the use of equipment and materials, and swift changes in the BSN curriculum [11]. Apparently, student nurses have different insights towards their training environment [12]. Thus, the faculty and preceptors should be mindful about the actual experiences and feedback from the students. This helps promote proficiency when working in different clinical environment.

Clinical experiences are integral part of nursing education which prepare student nurses to engage in "doing" as well as "knowing" the clinical principles in practice. Clinical practice encourages students to become critical thinkers and problem-solvers. The clinical environment is both complex and collective which influences the learning outcomes of the students. Exploring the students' clinical experiences gives insight of the education mechanism and allows instructors to enhance the students' learning opportunities [13].

In clinical practice, difficulties in learning were identified including deficient knowledge on the scope of nursing practice, theory-practice gap, conflict between educational objectives and expectations, and unsatisfactory supervision and feedback $[9,14,15]$. At present, nursing education in Saudi Arabia receives surprisingly little attention in research in terms of clinical practice. Several studies showed that Saudi students have been found to encounter stress levels above the mean where assignments and workloads are the most common sources [16]. Anxiety during clinical exposures has been identified as a primary reason for student nurses' intent to leave the BSN program. However, the students are less anxious when they learn and gain confidence [17]. Alleviating anxiety enhances motivation towards completion of the program which perhaps can resolve the chronic shortage of nurses in Saudi Arabia. According to literature reviews, there were limited studies on clinical experiences of Saudi student nurses. Thus, this research aimed to explore their clinical challenges and its implications on learning outcomes when in hospitals and other health care facilities in Saudi Arabia.

\section{Materials and Methods}

2.1. Design. A descriptive cross-sectional design was used. A survey was done to determine the challenges encountered by student nurses in clinical areas.

2.2. Sample and Settings. Calculation for the sample size, with an effect size of $0.5, p$ value of 0.05 , and power of 0.95 , yielded 211. The researcher recruited 220 out of the 463 student nurses from RNP and NBP. The study was conducted in the nursing college in a government university in Riyadh which started the BSN program since 1976 in Saudi Arabia. Inclusion criteria for student nurses included (1) Saudi nationals, (2) from academic level 5 to 8, and (3) have clinical experiences. Students from the academic level 1 to 4 and those without clinical experiences were excluded from the study.

2.3. Ethical Considerations. The study was granted ethical clearance by the Institutional Review Board of King Saud University Medical City. The researchers visited the clinical areas and classrooms after the learning sessions of the students. The respondents were made fully aware of the purpose of the study and their right to withdraw. The respondents were not coerced and were ensured of the confidentiality and anonymity of the research data and sources. Those who voluntarily agreed to participate signed the informed consent.

2.3.1. Development of the Tool. A self-report questionnaire was utilized in the current study which is composed of three parts. The second and third were developed and presented in English language by one of the authors of this study to pursue scientific investigation among nursing students. The derivation of these parts from related literature trailed five steps which involved understanding the background, conceptualization, formatting, and data analysis and establishing reliability. In step 1 , the authors aimed to assess the population of nursing students. The primary goal was to gain a thorough understating of the clinical experiences specifically on challenges through research and literature review. In step 2, contents from the reviewed literature were used to formulate statements and identify variables to conceptualize the research tool. There were three main concepts derived from the search and conceptualization which included unsupportive learning environment, ambiguous evaluation, and insufficient competence. These were contained in this study as the second part. The third part refers to implications of the experiences to learning outcomes. Formatting of the tool was done in step 3, wherein a 5-point Likert scale was preferred to determine the agreement to the obstacles experienced. A panel of 3 experts in nursing education and clinical practice examined the validity of the tool in step 4 . Results showed a scale level content validity index (S-CVI) of 0.95 which indicated relevance of the items to what the test intended to measure. Finally, in step 5, a pilot study was conducted with 30 nursing students in clinical settings in 
order to determine internal consistency. The reliability test showed a coefficient (alpha) of 0.83 for second part and 0.88 in the third which indicated acceptability in using the developed tool. Similar findings were yielded for the subscales in insufficient competence $(\alpha=0.85)$, ambiguous evaluation $(\alpha=0.85)$, and unsupportive learning environment $(\alpha=0.83)$.

2.3.2. Demographic Data. The first part comprised academic level, age, gender, civil status, academic status, and GPA.

\subsubsection{Challenges in the Clinical Environment (CCET).} The second and third parts of the instrument were selected in the current study due to the similarity of the items with the clinical learning objectives for nursing students in their clinical training program. In the second part, there were 25 items which were either adapted or modified for equivalency with the clinical learning objectives in the current study. It has three subscales which included insufficient competence (9 items), ambiguous evaluation (6 items), and unsupportive learning environment (10 items). The third part has 13 items which was used to identify the implications of the challenges towards the nursing students' learning outcomes. Both second and third parts of the questionnaire were rated by the respondents using Likert-type scales with five responses ranging from 0 to 4 indicating from strongly disagree to strongly agree. Higher mean scores indicate that clinical challenges were encountered either frequently (2.40 to 3.19) or always (3.20 to 4.00 ). Lower mean scores such as $0.00-$ 0.79 indicate never, $0.80-1.59$ means rarely, and $1.60-2.39$ as occasionally.

2.3.4. Translation, Cross-Cultural Adaptation, and Validity of the Instrument. There were five stages adopted in translating, cross-cultural adaptation, and validation of the CCET into Arabic language and culture following Beaton et al. [18]. In stage 1, two bilingual experts translated the English items into Arabic language. The objective at this stage was attained using the equivalency of the English items into Arabic which resulted into cross-cultural adaptation. Review and synthesis of the Arabic translations were done by two bilingual native Arabic experts who evaluated the semantic, idiomatic, and conceptual equivalence of the Arabic translations. Consensus was attained on the Arabic translation after minor discrepancies were resolved. Back translation of the Arabic version to English by expert Arabic to English translators was accomplished in stage 3. In stage 4, review of the Arabic translation and the back-translated versions was completed by two bilingual experts for consensus validation of the prefinal version, and face-validated version was obtained. To ensure robustness of the Arabic version, the questionnaire was subjected to further validity tests using SCVI. The test computed the proportion of items that rated quite or very relevant by each of those who rated by following the procedures set by Polit and Beck [19]. Five experts examined and rated the individual items. The validation test yielded an overall S-CVI of 0.98 . The results suggested that the items in the second and third parts of the instrument are important and relevant. Thus, the Arabic version of the instrument is acceptable and has very good content validity. In stage 5 , the pretesting of the Arabic version of instrument was participated by 20 Saudi nursing students. They evaluated and provided feedback that the items were easy to read and understand. The students completed the questionnaire within 8 to 10 minutes.

2.3.5. Reliability of the Instrument. In this section, the Arabic version of the CCET was subjected to the interitem correlation coefficient test using the data from the pretest results. The second and third parts yielded Cronbach's $\alpha=$ 0.80 and Cronbach's $\alpha=0.87$, respectively, indicating good internal consistency. The results were consistent with the subscales of the second part such as insufficient competence ( $\alpha=0.82$ ), ambiguous evaluation $(\alpha=0.87)$, and unsupportive learning environment $(\alpha=0.86)$. Both second and third parts yielded very good reliability scores for the Arabic version. Therefore, the Arabic CCET was used in the current study on the basis of the robustness in translation, cultural adaptation, validation, and reliability tests.

2.4. Data Collection Procedures. Recruitment of respondents was done by visiting both female and male campuses of the selected nursing college and clinical areas. Respondents who agreed to participate were invited to respond to the survey questionnaire. The completed questionnaires were sealed in envelopes and dropped inside the allocated boxes.

2.5. Data Analysis. Data were analyzed using the Statistical Package for the Social Science (SPSS) version 23. Descriptive statistics such as frequency, percentage, mean, and standard deviation were used to describe the demographic characteristics and identify the clinical challenges. The Spearman correlation coefficient and Mann-Whitney $U$ test were used to identify correlation and differences among selected variables.

\section{Results and Discussion}

As shown in Table 1, the majority of respondents belonged to academic level 8 (61.8\%). A little more than half of the respondents were aged 21-25 years (56.4\%). The majority were females $(67.3 \%)$, single $(70.0 \%)$, enrolled in the RNP program $(63.2 \%)$ and with a very satisfactory grade point average $(M=3.78$; $\mathrm{SD}=0.66)$.

Table 2 showed that the respondents occasionally experienced clinical challenges $(M=1.82)$. Ambiguous evaluation $(M=1.97)$ was the most commonly experienced component of clinical challenges followed by unsupportive learning environment $(M=1.87)$ and insufficient development of competencies $(M=1.69)$. The respondents observed that "too much requirements" $(M=2.25)$, "having exams irrelevant to clinical concepts" $(M=1.99)$, and the "lack of reliable methods for evaluation" $(M=1.94)$ were the most common clinical challenges they faced whenever their 
clinical performance is evaluated. It is also apparent that the clinical environment became commonly unsupportive to learning when the "theoretical knowledge was not applied to practice" $(M=2.22)$, there was "insufficient opportunities to perform procedures" $(M=2.14)$, and when "no staff nurses cooperated and trusted them" $(M=2.12)$. The respondents also commonly answered that their competencies were insufficiently developed wherein they were challenged with "preparation for clinical exposure" $(M=2.02)$, "theorypractice translation" $(M=1.80)$, and "planning patient care" $(M=1.76)$.

Findings in Table 3 showed that it was occasional for these challenges to have implications in the learning outcomes of the student nurses $(M=1.97)$. The existing "gap between theory and practice" $(M=2.27)$, "distrust to clinical nurses" $(M=2.22)$, "poor trust to faculty" $(M=2.05)$, "missed learning opportunities" $(M=2.03)$, and "fear of performing procedures" ( $M=2.01)$ were the most commonly perceived implications of the clinical challenges towards learning outcomes.

In Table 4, the Spearman correlation coefficient showed significant relationship between age and ambiguous evaluation $(p=0.04)$, academic level and insufficient development of competence $(p=0.02)$, and GPA and implications of challenges to learning outcomes $(p=0.02)$.

The Mann-Whitney $U$ test showed that there was a significant difference in terms of civil status and their perception towards insufficient development of competencies ( $p$ value $<0.05$ ). Hence, single student nurses have experienced more challenging experiences towards competency development in clinical areas. Moreover, the stream of study was also significantly different with clinical competency development $(p=0.04)$ and the implications of challenges to learning outcomes $(p=0.04)$ (Table 5). Students in the RNP faced more clinical challenges than those in the NBP in terms of competency development and achievement of good learning outcomes. Several students described feeling intrusive, uncomfortable, and even unwelcomed in clinical areas because of the attitudes and behavior of clinicians. Findings of this study highlighted the importance of clinicians and academic nurses working together to ensure that nursing students, who represent the future of the profession, are provided with the best possible opportunities for clinical learning.

\section{Discussion}

Similar to previous studies in other countries, the Saudi student nurses also encountered occasional challenges in the clinical settings. In terms of competency development, the students in the higher academic levels, single, and those enrolled in RNP encountered more challenges. The BSN curriculum follows a ladderized approach wherein competencies become more comprehensively challenging as student nurses advance to higher academic levels. Thus, those in their junior and senior year levels are expected to encounter more difficulties which need more advanced mentoring approach in clinical teaching. Students in the BNP were already exposed, oriented, or even currently working in
Table 1: Profile of the respondents.

\begin{tabular}{lcc}
\hline Characteristics & Categories & $N(\%)$ \\
\hline & V & $22(10.0)$ \\
Academic level & VI & $38(17.3)$ \\
& VII & $24(10.9)$ \\
& VIII & $136(61.8)$ \\
Age group & $>20$ & $7(3.2)$ \\
& $21-25$ & $124(56.4)$ \\
& $26-30$ & $61(27.7)$ \\
Gender & $31-35$ & $26(11.8)$ \\
& $>36$ & $2(0.9)$ \\
Civil status & Male & $72(32.7)$ \\
& Female & $148(67.3)$ \\
Academic status & Single & $154(70)$ \\
GPA $M=3.78 ;$ SD $=0.66$ & Married & $65(29.5)$ \\
& Bridging nursing (BNP) & $81(36.8)$ \\
& & $139(63.2)$ \\
& Separated/divorce & $1(0.5)$ \\
& &
\end{tabular}

$N=220$; GPA: grade point average.

actual settings after successfully completing associate or diploma in nursing. Thus, they are less challenged of the tasks and adversaries because of their clinical experiences compared to those in RNP. Also, Saudi married students nurses are less restricted to socialization and have better financial sources than their counterparts. These factors may have contributed to their varied perceptions towards developing clinical competencies. Students with less social support and financial sources have difficulty in securing educational tools and were less motivated in completing the course. Furthermore, the study showed that the most perceived clinical challenges in competency development include inadequate preparation, failure in translating theory into practice, and difficulty in planning patient care. Despite the theoretical concepts and practical application of nursing skills done in simulation laboratories prior to clinical exposure, the Saudi student nurses still considered their preparation for clinical exposure as inadequate. The challenges in the preparation to handle real patients and difficulty in planning care affect their willingness to participate in hospital procedures. This also affects their ability to acquire essential knowledge and skills in performing nursing care. Wawire et al. [20] found out that consistent exposure to return demonstration utilizing psychomotor skills and critical reasoning enhance the proficiency of the student nurses and expand their confidence in clinical exposures. Heidari and Norouzadeh [21] found that the tasks and objectives in planning patient care received low ratings at the beginning made the student nurses' learning more challenging. Furthermore, bringing together the context of theory in lectures and manuals in clinical areas is a recommended strategy in resolving the theory-practice gap. According to Okoronkwo et al. [22], the acquisition of the nursing competencies among students requires effective clinical teaching. This secures their ability to deliver safe quality nursing care to their patients. Rafiee et al. [23] recommended that despite of the limitations in clinical teaching methods, the evaluation of the students' clinical competencies by the faculty must be approriate and 
TABLE 2: Clinical challenges experienced by the Saudi nursing students.

\begin{tabular}{|c|c|c|}
\hline & Weighted mean & Descriptive meaning \\
\hline \multicolumn{3}{|l|}{ (A) Insufficient competence } \\
\hline (1) Difficulty in planning care for patient & 1.76 & Occasionally \\
\hline (2) Inadequate preparation for clinical exposure & 2.02 & Occasionally \\
\hline $\begin{array}{l}\text { (3) Lack of basic knowledge and skills to carryout } \\
\text { common procedures }\end{array}$ & 1.63 & Occasionally \\
\hline $\begin{array}{l}\text { (4) Difficulty in interacting with clients and other } \\
\text { health workers }\end{array}$ & 1.61 & Occasionally \\
\hline $\begin{array}{l}\text { (5) Ïnefficiency in teaching-learning process } \\
\text { regarding the acquisition of knowledge and practical } \\
\text { skills }\end{array}$ & 1.75 & Occasionally \\
\hline $\begin{array}{l}\text { (6) Inappropriate approach in using instructional } \\
\text { strategies }\end{array}$ & 1.59 & Rarely \\
\hline $\begin{array}{l}\text { (7) Noncompliance to the standards of caring } \\
\text { principles }\end{array}$ & 1.57 & Rarely \\
\hline (8) Failure in translating theory into practice & 1.80 & Occasionally \\
\hline $\begin{array}{l}\text { (9) Health care services are not systematic and } \\
\text { scientific }\end{array}$ & 1.53 & Rarely \\
\hline Overall rating & 1.69 & Occasionally \\
\hline \multicolumn{3}{|l|}{ (B) Ambiguous evaluation } \\
\hline (1) Lack of sufficient reliability of clinical evaluation & 1.94 & Occasionally \\
\hline $\begin{array}{l}\text { (2) Unsatisfactory clinical supervision and } \\
\text { monitoring }\end{array}$ & 1.93 & Occasionally \\
\hline (3) Evaluation is not specific and objective & 1.81 & Occasionally \\
\hline $\begin{array}{l}\text { (4) The criteria indicated in the evaluation tool are } \\
\text { not applicable }\end{array}$ & 1.92 & Occasionally \\
\hline (5) Too many requirements to submit & 2.25 & Occasionally \\
\hline $\begin{array}{l}\text { (6) Examination given is not relevant to the clinical } \\
\text { concepts }\end{array}$ & 1.99 & Occasionally \\
\hline Overall rating & 1.97 & Occasionally \\
\hline (C) Unsupportive learning environment & Weighted mean & Descriptive meaning \\
\hline (1) Behavioral and verbal violence of the health team & 1.43 & Rarely \\
\hline (2) Students and instructors do not accept criticism & 1.74 & Occasionally \\
\hline $\begin{array}{l}\text { (3) Unprofessional behaviors of the nurses at the } \\
\text { bedside }\end{array}$ & 1.61 & Occasionally \\
\hline $\begin{array}{l}\text { (4) Lack of opportunity to experience and perform } \\
\text { the technique and operational procedures }\end{array}$ & 2.14 & Occasionally \\
\hline $\begin{array}{l}\text { (5) Daily routine functions without application of the } \\
\text { learned theories }\end{array}$ & 2.22 & Occasionally \\
\hline (6) Varied training cases in the ward & 2.05 & Occasionally \\
\hline $\begin{array}{l}\text { (7) Lack of cooperation and distrust of clinical nurses } \\
\text { with students }\end{array}$ & 2.12 & Occasionally \\
\hline (8) Patients and significant others are uncooperative & 1.71 & Occasionally \\
\hline (9) Unclear school policies and regulations & 1.79 & Occasionally \\
\hline (10) Inadequate support from college/administration & 1.91 & Occasionally \\
\hline Overall & 1.87 & Occasionally \\
\hline
\end{tabular}

Mean range: 0.00-0.79 (never), 0.80-1.59 (rarely), 1.60-2.39 (occasionally), 2.40-3.19 (frequently), and 3.20-4.00 (always).

comprehensive. The lack of awareness and competence of the faculty or preceptors can impact the learning outcomes negatively [9].

The age of the student nurses has also been found to be associated with challenges in clinical evaluation. Senior students are more challenged in performing nursing tasks in clinical settings than the new students. The last few years of clinical education demand higher competencies and appraisal which commonly prompt obstacles among the student nurses. Also, the study showed that multiple requirements, irrelevance of clinical concepts to exams, and lack of reliability were the most common challenges in clinical evaluation. Requirements and examinations are introduced to test the cognitive and psychomotor domains. These are necessary for the development of the essential knowledge, skills, and attitude among student nurses. A study conducted in Ethiopia showed that student nurses raised their concerns regarding inconsistencies in clinical evaluation [22]. According to Imanipour and Jalili [24], some student nurses showed disagreement of the inappropriateness of the clinical evaluation methods in Iran. The challenges found among Saudi student nurses are 
TABLE 3: Implications of clinical challenges towards learning outcomes.

\begin{tabular}{lcc}
\hline Items & Weighted mean & Descriptive meaning \\
\hline (1) Poor quality of patient care & 1.62 & Occasionally \\
(2) Not satisfied with learning the necessary skills for & 1.95 & Occasionally \\
nursing employment & 2.03 & Occasionally \\
(3) Learning opportunities for the students were lost & 1.95 & Occasionally \\
(4) Loses energy during clinical practice & 1.85 & Occasionally \\
(5) Loses confidence for nursing care & 1.83 & Occasionally \\
(6) Students are afraid to ask questions related to & & Occasionally \\
patient care & 1.84 & Occasionally \\
(7) Withdrawal of the student from performing the & 2.01 \\
procedure & 2.27 & Occasionally \\
(8) Fear of performing nursing procedure & 2.00 \\
(9) Gap between theory and practice & Occasionally \\
(10). Creates a feeling of depression and & 2.22 \\
(11) Distrust of clinical nurses with students & 1.99 & Occasionally \\
(12) Lessens the interest of the students to remain in & 2.05 & Occasionally \\
the profession & 1.97 & Occasionally \\
Overall & Occasionally \\
\hline
\end{tabular}

Mean range: 0.00-0.79 (never), 0.80-1.59 (rarely), 1.60-2.39 (occasionally), 2.40-3.19 (frequently), and 3.20-4.00 (always).

TABLe 4: Relationship of age, yearly academic level, and GPA towards clinical challenges and implications.

\begin{tabular}{|c|c|c|c|}
\hline Challenges and implications & Spearman rank correlation coefficient & $p$ value & Remarks \\
\hline \multicolumn{4}{|l|}{ Age } \\
\hline Insufficient competence & -0.103 & 0.128 & Not significant \\
\hline Ambiguous evaluation & 0.138 & ${ }^{*} 0.041$ & Significant \\
\hline Unsupportive learning environment & 0.024 & 0.727 & Not significant \\
\hline Implications to learning outcomes & 0.080 & 0.235 & Not significant \\
\hline \multicolumn{4}{|l|}{ Academic level } \\
\hline Insufficient competence & -0.153 & $* 0.023$ & Significant \\
\hline Ambiguous evaluation & -0.009 & 0.890 & Not significant \\
\hline Unsupportive learning environment & -0.093 & 0.168 & Not significant \\
\hline Implications to learning outcomes & -0.039 & 0.565 & Not significant \\
\hline \multicolumn{4}{|l|}{$G P A$} \\
\hline Insufficient competence & -0.013 & 0.850 & Not significant \\
\hline Ambiguous evaluation & 0.100 & 0.138 & Not significant \\
\hline Unsupportive learning environment & 0.086 & 0.206 & Not significant \\
\hline Implications to learning outcomes & 0.155 & ${ }^{*} 0.021$ & Significant \\
\hline
\end{tabular}

${ }^{*} p$ value significant at $<0.05$.

comparable with those identified by Heidari and Norouzadeh [21] which included poor awareness on the objectives and methods of evaluation. According to Schönwetter et al. [25], it is apparent that the evaluative methods such as exam and assignments be made thoroughly, fair and timely. The results should be elaborated with feedback since these are important components of effective clinical teaching. Thus, the preceptors should orient the student nurses of the criteria in evaluating their clinical performances in order to resolve the ambiguity.

The most common challenges in terms of learning support in the clinical environment include poor application of learned theories, missed opportunities to perform techniques and procedures, and lack of cooperation and trust with staff nurses. According to Rajeswaran [26], hospital wards directly influence students' learning in the clinical setting. Inadequate exposure to varied cases in wards, theory-practice gap, and lack of harmony, communication, and interpersonal relationship negatively affect the clinical learning of the student nurses [27]. Al Mutair's [9] findings supported that clinical teaching in Saudi Arabia needs to upgrade its proficiency and recommends more immersion in active clinical settings so that student nurses can translate their knowledge into skills. Regular clinical exposure will also help student nurses establish a better working relationship with the staff and their patients.

As for implications towards learning outcome, student nurses with higher GPAs and those in RNP experienced problems in achieving good learning outcomes when faced with clinical challenges. The clinical experience of those in 
TABLE 5: Differences of students' perception towards clinical challenges and implications in terms of civil status and stream of study.

\begin{tabular}{|c|c|c|c|c|c|}
\hline & & Mean & Mann-Whitney $U$ value & $p$ value & Remarks \\
\hline \multicolumn{6}{|l|}{ Gender } \\
\hline \multirow{2}{*}{ Insufficient competence } & Male & 1.7546 & 213.00 & 0.795 & Not significant \\
\hline & Female & 1.6689 & & & \\
\hline \multirow{2}{*}{ Ambiguous evaluation } & Male & 2.0162 & 5220.00 & 0.807 & Not significant \\
\hline & Female & 1.9527 & & & \\
\hline \multirow{2}{*}{ Unsupportive learning environment } & Male & 1.9556 & 5108.00 & 0.619 & Not significant \\
\hline & Female & 1.8324 & & & \\
\hline \multirow{2}{*}{ Implications to learning outcomes } & Male & 1.9113 & 4879.5 & 0.311 & Not significant \\
\hline & Female & 1.9974 & & & \\
\hline \multicolumn{6}{|l|}{ Civil status } \\
\hline \multirow{2}{*}{ Insufficient competence } & Single & 1.7951 & 3926.00 & *0.012 & Significant \\
\hline & Married & 1.4769 & & & \\
\hline \multirow{2}{*}{ Ambiguous evaluation } & Single & 2.0000 & 4721.00 & 0.506 & Not significant \\
\hline & Married & 1.9256 & & & \\
\hline \multirow{2}{*}{ Unsupportive learning environment } & Single & 1.8838 & 4622.00 & 0.370 & Not significant \\
\hline & Married & 1.8585 & & & \\
\hline \multirow{2}{*}{ Implications to learning outcomes } & Single & 1.9725 & 4969.00 & 0.933 & Not significant \\
\hline & Married & 1.9751 & & & \\
\hline \multicolumn{6}{|l|}{ Stream of study } \\
\hline \multirow{2}{*}{ Insufficient competence } & BS & 1.7786 & 4705.50 & ${ }^{*} 0.042$ & Significant \\
\hline & Bridging & 1.5569 & & & \\
\hline \multirow{2}{*}{ Ambiguous evaluation } & BS & 1.9281 & 5250.00 & 0.403 & Not significant \\
\hline & Bridging & 2.0514 & & & \\
\hline \multirow{2}{*}{ Unsupportive learning environment } & BS & 1.8770 & 5368.00 & 0.565 & Not significant \\
\hline & Bridging & 1.8654 & & & \\
\hline \multirow{2}{*}{ Implications to learning outcomes } & $\mathrm{BS}$ & 1.8843 & 4698.00 & ${ }^{*} 0.041$ & Significant \\
\hline & Bridging & 2.1149 & & & \\
\hline
\end{tabular}

${ }^{*} p$ value significant at $<0.05$.

RNP is lesser than those in NBP. This explains their difficulties in adapting to the clinical learning environment which most probably affects their learning outcomes than those in NBP. Student nurses with higher GPAs are constantly challenged to meet the necessary competencies which must be satisfactorily achieved as competency development advances to higher levels. Aiming for higher GPA demands hardwork, focus, and countless trials to master the clinical procedures in order to obtain a higher mark. The gap between theory and practice, distrust between staff nurses and students, and less learning opportunities were the highest among the implications of clinical obstacles to learning. In a similar study, theory-practice gap in nursing has been an issue of concern for many years because it has been shown to delay student learning [28]. The students' experiences in clinical nursing laboratories, were perceived as different and not as authentic with the experiences in real clinical settings [29]. For theory to be translated into practice, it is necessary to update procedure manuals and protocols with current information based on the Saudi Nursing Council standards as these facilitate the mastery of the essential skills and procedures in the clinical settings. It is so pivotal to harmonize the content between what is being taught in classrooms and what is included in the clinical manuals in actual settings. The clinical manuals are based on research findings that do not necessarily contain what are stipulated in the nursing curriculum according to the World Health Organization (WHO) guidelines [30]. The challenges encountered in the clinical settings negatively affect the student's learning opportunities leading to not trusting their teachers or preceptors. Learning opportunities become limited without the support of the staff nurses, faculty, and their patients. According to Jackson and Mannix [31], behaviors that students found unhelpful to their learning were often passive rather than active and made students feel acutely aware of being unwelcomed in the clinical area. Students perceive nurses who have helpful behaviors as those who are understanding and being friendly, showing interest, and responding to their queries. The clinicians and academicians must work together to ensure that student nurses are provided with the best possible opportunities for clinical learning [29]. The students' knowledge, critical thinking ability, and confidence are enhanced when with instructors who are trustworthy, well-experienced, knowledgeable, and act as coaches [32].

Another aspect of the highest implications towards learning outcome is the loss of learning opportunities. This is supported by Vallant and Neville [33] who found out that while clinical setting is an imperative ground for learning, there are issues affecting student nurses' ability to acquire all of the learning opportunities that arose. Overloaded facilities [34], apparent behavior of nurses towards students [14], and theory-practice gap [28] were among the challenges that deter learning in the clinical setting. Significantly, poor quality of patient care is a less perceived implication to learning. This is congruent in the study of Oskay et al. [35], 
where findings revealed a high satisfaction rate with the care received from student nurses indicating that they were able to meet patients, needs. This served as an indicator of the quality of care provided by future nurses. Mukumbang and Oluyinka [36] reported that patients have positive experiences with student nurses and perceived that students were "helpful," "did a very good job," "quite excellent," "caring," "friendly," "very good," and "wonderful." The patients commended the quality of nursing care rendered by the student nurses. Notably, withdrawal of students from performing procedures has lesser implication to the learning outcomes in the clinical setting. This comes in contrast with the study of Baraz et al. [30], which revealed that students were less involved in clinical activities due to various factors which had negative impact on them like when encountering health-threatening situations.

The perceived clinical challenges must be addressed to create a positive learning environment for student nurses. As cited by Papp et al. [37], student nurses value clinical practice and the possibilities it offers in helping students become professional nurses. Several studies have identified students' perceptions of the clinical learning environment with higher levels of individualization, innovation in teaching and learning strategies, student involvement, personalization, and task orientation. As cited by Mabuda et al. [34], a clinical setting that is rich in learning experiences, but lacking a supportive environment, discourages learners from seeking experience. Consequently, learning and growth opportunities will be diminished. On the other hand, a setting with limited experiences but rich in support may provide opportunities for student nurses in identifying health-care delivery needs and ways of addressing them. Therefore, the school should be able to provide a suitable clinical learning environment, so that theory and practice would complement each other [37]. Students' clinical learning challenges should be identified and must be acted upon by eliminating or adjusting them to create more learning opportunities, improving the achievement of learning goals, and provision and prioritization of the needed competencies. Moreover, addressing the concerns on clinical challenges can help meet the complex demands of caring, resolve theory-practice gap, and improve the quality of health care services [30]. As such, clinical teaching and learning should focus on the essential knowledge, skills, and attitude in nursing practice [14].

\section{Conclusions}

In conclusion, Saudi student nurses perceived clinical evaluation as the most common challenge when exposed in clinical practice. However, it is only occasional that they encounter this problem together with inadequate support, insufficient competency development, and poor implications to learning outcomes. The GPA, academic level, stream of study, civil status, and age varied or linked with the challenges and in achieving good learning outcomes. Investigating the viewpoints of the student nurses regarding their difficulties in the clinical learning environment will serve as basis in developing strategies that will help in the achievement of positive clinical learning outcomes. Adequate preparation of students in clinical exposure and effective application of theoretical concepts in clinical practice are recommended. Also, improvement in clinical evaluation may be implemented by giving relevant exams and performing valid competency assessments. Overall, creating a harmonious relationship between students, faculty, and hospital staff will set the clinical environment ideal for learning.

\section{Data Availability}

The data used to support the findings of this study are available from the corresponding author upon request.

\section{Conflicts of Interest}

The authors declare that there are no conflicts of interest regarding the publication of this paper.

\section{Acknowledgments}

The authors are thankful to the Deanship of Scientific Research through the Research Center at the College of Nursing, King Saud University, for the support of this research project. Furthermore, sincere appreciation is also addressed by the authors to the Institution Review Board of King Saud University Medical City for the ethical approval of this research project.

\section{References}

[1] A. Aboshaiqah, "Strategies to address the nursing shortage in Saudi Arabia," International Nursing Review, vol. 63, no. 3, pp. 499-506, 2016.

[2] G. Tumulty, "Professional development of nursing in Saudi Arabia," Journal of Nursing Scholarship, vol. 33, no. 3, pp. 285-290, 2001.

[3] L. A. Gazzaz: Saudi nurses' perceptions of nursing as an occupational choice: a qualitative interview study, Ph.D. dissertation, University of Nottingham, Nottingham, UK, 2009, http://eprints.nottingham.ac.uk/11863/.

[4] World Health Organization, "Global standards for the initial education of professional nurses and midwives," WHO/HRH/ HPN/08.6, 2009, http://apps.who.int/iris/bitstream/10665/ 44100/1/WHO_HRH_HPN_08.6_eng.pdf.

[5] V. L. Nahas, "Humour: a phenomenological study within the context of clinical education," Nurse Education Today, vol. 18, no. 8, pp. 663-672, 1998.

[6] R. A. Al-Naggar, M. Abdulghani, M. T. Osman et al., "The Malaysia DREEM: perceptions of medical students about the learning environment in a medical school in Malaysia," Advances in Medical Education and Practice, vol. 5, pp. 177-184, 2014.

[7] P. Pai, V. Menezes, Srikanth, A. Subramanian, and J. Shenoy, "Medical students' perception of their educational environment," Journal of Clinical and Diagnostic Research, vol. 8, no. 1, pp. 103-107, 2014.

[8] S. V. Dunn and B. Hansford, "Undergraduate nursing students' perceptions of their clinical learning environment," Journal of Advanced Nursing, vol. 25, no. 6, pp. 1299-1306, 1997. 
[9] A. Al Mutair, "Clinical nursing teaching in Saudi Arabia challenges and suggested solutions," Journal of Nursing and Care, vol. s1, pp. 1-4, 2015.

[10] Y. Hosoda, "Development and testing of a clinical learning environment diagnostic inventory for baccalaureate nursing students," Journal of Advanced Nursing, vol. 56, no. 5, pp. 480-490, 2006.

[11] M. S. Ahmad, A. Bhayat, H. T. Fadel, and M. Mahrous, "Comparing dental students' perceptions of their educational environment in Northwestern Saudi Arabia," Saudi Medical Journal, vol. 36, no. 4, pp. 477-483, 2015.

[12] S. Miles, L. Swift, and S. J. Leinster, "The dundee ready education environment measure (DREEM): a review of the adoption and use," Medical Teacher, vol. 34, no. 9, pp. e620-e634, 2012.

[13] E. Papastavrou, E. Lambrinou, H. Tsangari, M. Saarikoski, and H. Leino-Kilpi, "Student nurses experience of learning in the clinical environment," Nurse Education in Practice, vol. 10, no. 3, pp. 176-182, 2010.

[14] L. Jamshidi, "The challenges of clinical teaching in nursing skills and lifelong learning from the standpoint of nursing students and educators," Procedia-Social and Behavioral Sciences, vol. 46, pp. 3335-3338, 2012.

[15] S. Kilminster, D. Cottrell, J. Grant, and B. Jolly, "AMEE Guide No. 27: effective educational and clinical supervision," Medical Teacher, vol. 29, no. 1, pp. 2-19, 2007.

[16] S. H. Alsaqri, "Stressors and coping strategies of the Saudi nursing students in clinical training: a cross-sectional study," Education Research International, vol. 2017, Article ID 4018470, 8 pages, 2017.

[17] S. M. Melincavage, "Student nurses' experiences of anxiety in the clinical setting," Nurse Education Today, vol. 31, no. 8, pp. 785-789, 2011.

[18] D. E. Beaton, C. Bombardier, F. Guillemin, and M. B. Ferraz, "Guidelines for the process of cross-cultural adaptation of self-report measures," Spine, vol. 25, no. 24, pp. 3186-3191, 2000.

[19] D. F. Polit and C. T. Beck, "The content validity index: are you sure you know that's being reported? Critique and recommendations," Research in Nursing and Health, vol. 29, no. 5, pp. 489-497, 2006.

[20] K. A. Wawire, S. Rogers, O. Claudio et al., "Challenges experienced by undergraduate nursing students during their clinical rotations," International Journal of Novel Research in Interdisciplinary Studies, vol. 1, no. 1, pp. 26-37, 2014.

[21] M. R. Heidari and R. Norouzadeh, "Nursing students' perspectives on clinical education," Journal of Advances in Medical Education and Professionalism, vol. 3, no. 1, pp. 3943, 2015.

[22] I. Okoronkwo, J. Onyia-Pat, M. Agbo, P. Okpala, and A. Ndu, "Students' perception of effective clinical teaching and teacher behaviour," Open Journal of Nursing, vol. 3, no. 1, pp. 63-70, 2013.

[23] G. Rafiee, M. Moattari, A. Nikbakht, J. Kojuri, and M. Mousavinasab, "Problems and challenges of nursing students' clinical evaluation: a qualitative study," Iranian Journal of Nursing and Midwifery Research, vol. 19, no. 1, pp. 41-50, 2014.

[24] M. Imanipour and M. Jalili, "Nursing teachers and students' perspective about clinical evaluation," Iranian Journal of Nursing Research, vol. 7, no. 25, pp. 17-26, 2012.

[25] D. J. Schönwetter, S. Lavigne, R. Mazurat, and O. Nazarko, "Students' perceptions of effective classroom and clinical teaching in dental and dental hygiene education," Journal of Dental Education, vol. 70, no. 6, pp. 624-635, 2006.

[26] L. Rajeswaran, "Clinical experiences of nursing students at a selected institute of health sciences in Botswana," Health Science Journal, vol. 10, no. 6, pp. 1-6, 2017.

[27] O. L. Chuan and T. Barnett, "Student tutor and staff perceptions of the clinical learning environment," Nurse Education in Practice, vol. 12, no. 4, pp. 192-197, 2012.

[28] F. Sharif and S. Masoumi, "A qualitative study of nursing student experiences of clinical practice," BMC Nursing, vol. 4, p. 6, 2005.

[29] J. Newton, S. Billet, B. Jolly, and C. M. Ockerby, "Lost in translation: barriers to learning in health professional clinical education," Learning in Health and Social Care, vol. 8, no. 4, pp. 315-327, 2009.

[30] S. Baraz, R. Memarian, and Z. Vanaki, "Learning challenges of nursing students in clinical environments: a qualitative study in Iran," Journal of Education and Health Promotion, vol. 4, p. 52,2015

[31] D. Jackson and J. Mannix, "Clinical nurses as teachers: insights from students of nursing in their first semester of study," Journal of Clinical Nursing, vol. 10, no. 2, pp. 270-277, 2008.

[32] J. Niederriter, D. Eyth, and J. Thoman, "Nursing students' perceptions on characteristics of an effective clinical instructor," SAGE Open Nursing, vol. 3, pp. 1-8, 2017.

[33] S. Vallant and S. Neville, "The relationship between student nurse and nurse clinical: impact on student learning," Nursing Praxis in New Zealand Inc., vol. 22, no. 3, pp. 23-33, 2006.

[34] B. T. Mabuda, E. Potgieter, and U. U. Alberts, "Student nurses' experiences during clinical practice in the Limpopo Province," Curationis, vol. 31, no. 1, pp. 19-27, 2008.

[35] U. Oskay, I. Gungor, and S. Basgol, "Evaluation of patients' satisfaction with nursing students' care on a perinatology ward," Journal of Nursing Education, vol. 54, no. 12, pp. 696-703, 2015.

[36] F. C. Mukumbang and A. Oluyinka, "Patients' experiences of being nursed by student nurses at a teaching hospital," Curationis, vol. 37, no. 1, pp. 1-10, 2014.

[37] I. Papp, M. Markkanen, and M. von Bonsdorff, "Clinical environment as a learning environment: student nurses' perceptions concerning clinical learning experiences," Nurse Education Today, vol. 23, no. 4, pp. 262-268, 2003. 


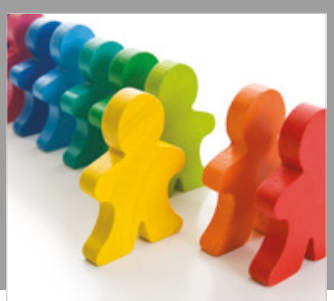

Autism

Research and Treatment
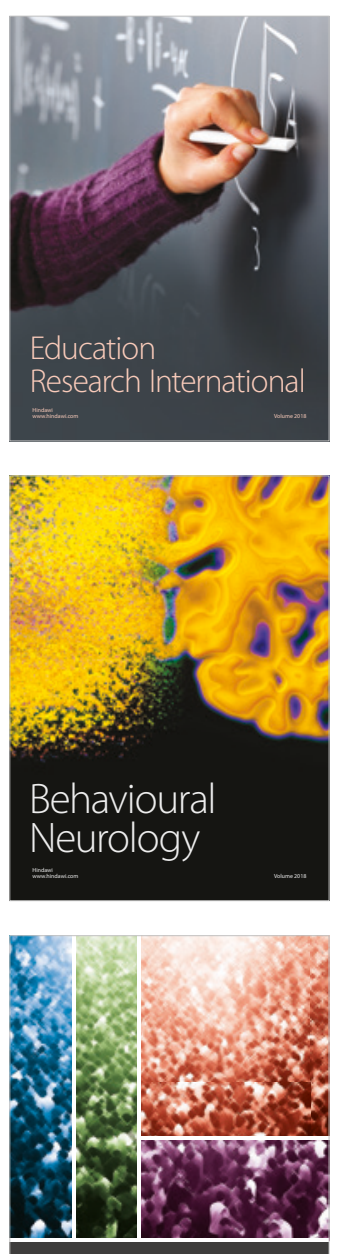

International Journal of

Population Research

$\underline{-m}$

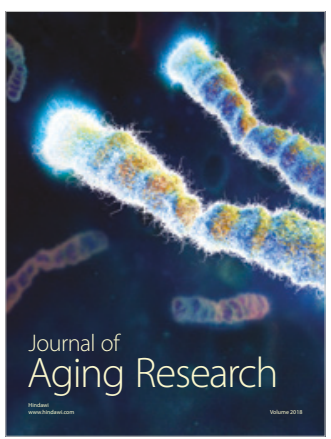

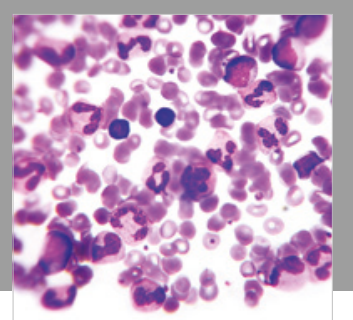

Pathology

Research International$$
=
$$

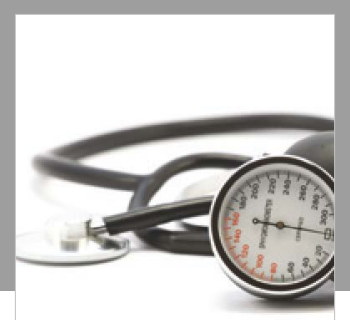

Nursing

Research and Practice

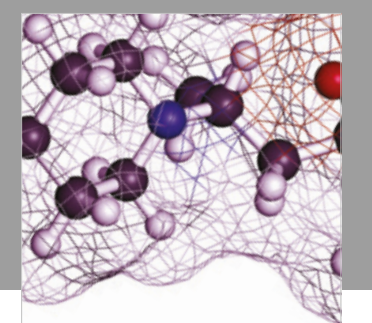

Pain

Research and Management

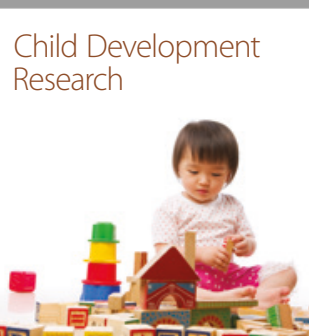

बाD

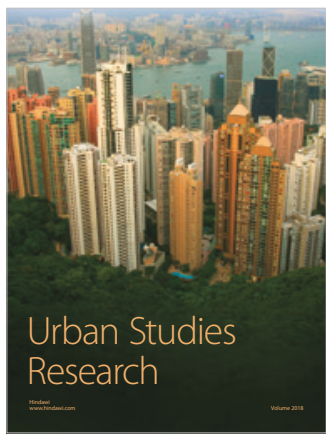

\section{Hindawi}

Submit your manuscripts at

www.hindawi.com
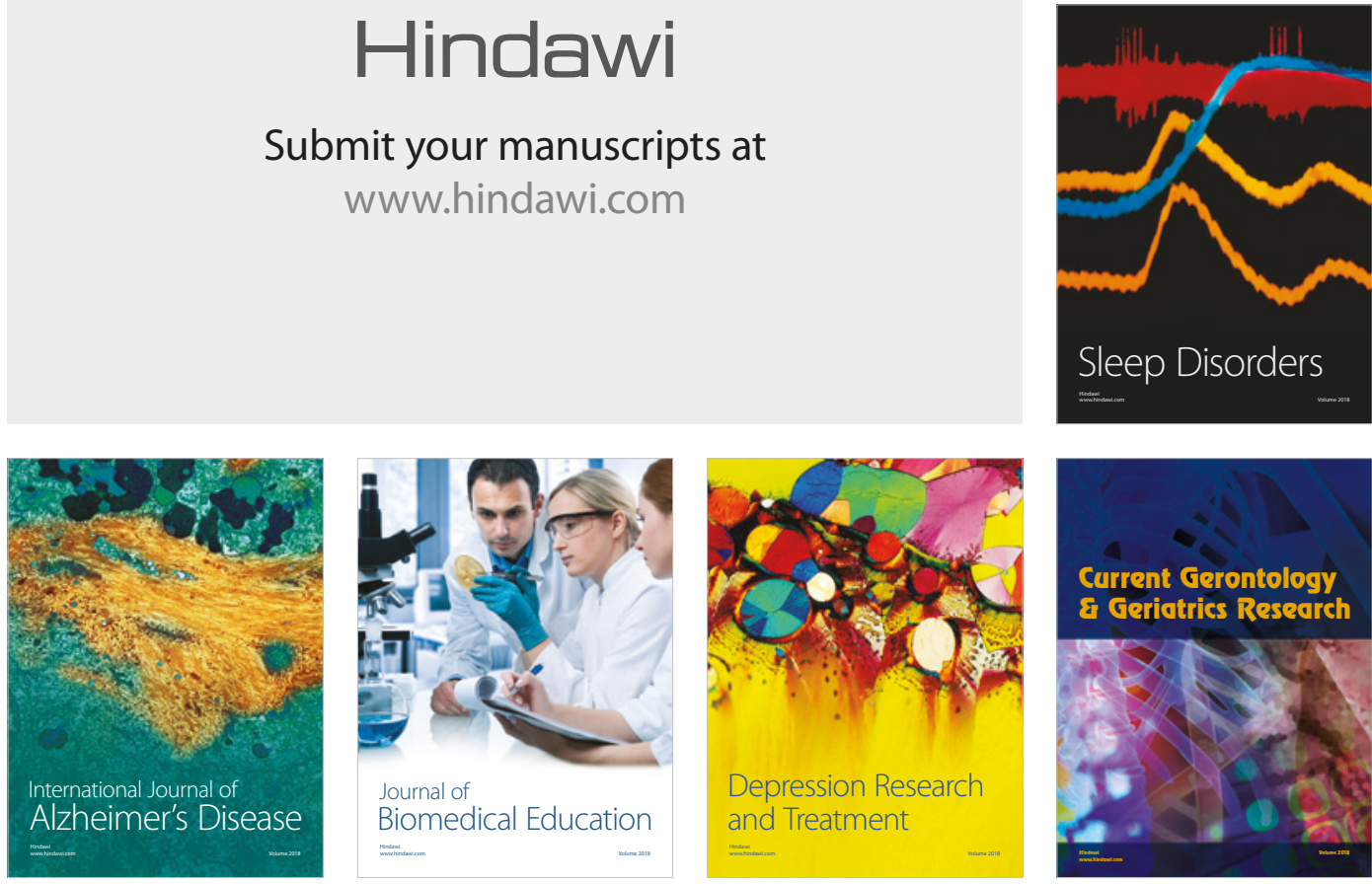

Journal of

Biomedical Education

$=$

smman

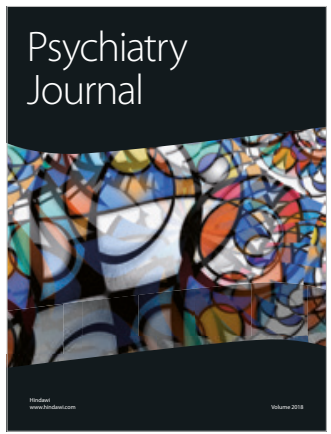

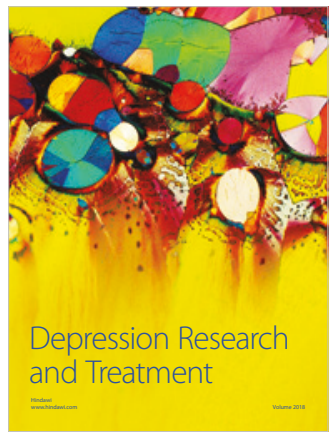
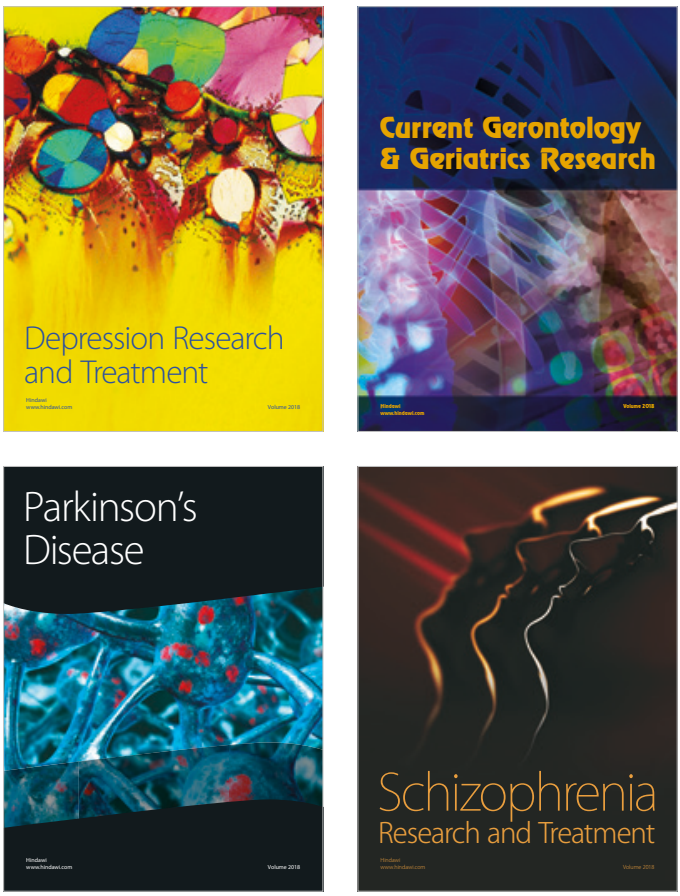